\title{
Reglas discursivas y normas morales
}

\section{(Discursive rules and moral norms)}

\author{
Alberto Mario DAMIANI
}

Recibido: 18 de julio de 2014

Aceptado: 7 de octubre de 2015

\section{Resumen}

El objetivo de este trabajo es explicar la conexión entre reglas discursivas y normas morales en el marco de la ética del discurso. El trabajo comienza con un análisis de la diferencia entre acción y operación y con una reconstrucción del concepto de discurso. Luego es presentada la diferencia y la relación entre ley y obligación. La conclusión es que la conexión entre acción y discurso posible está implícita en la noción de responsabilidad moral.

Palabras clave: regla, norma, discurso, acción, responsabilidad.

\begin{abstract}
The aim of this paper is to explain the connection between discursive rules and moral norms in the frame of discourse ethics. The paper begins with an analysis of the difference between action and operation and with a reconstruction of the concept of discourse. After that, the difference and the relationship between law and obligation are presented. The conclusion is that the connection between action and possible discourse is implicit in the notion of moral responsibility.
\end{abstract}

Keywords: rule, norm, discourse, action, responsibility.

La ética del discurso sostiene que las normas morales pueden fundamentarse mediante un procedimiento discursivo que presupone necesariamente ciertas reglas. Algunas de las críticas que ha recibido esta teoría ética advierten sobre la diferencia entre estas reglas y las normas morales. Mientras algunas críticas niegan el 
carácter ético-normativo de estas reglas, otras lo conceden pero señalan que sólo valen para quienes deciden participar en el discurso.

El objetivo de este trabajo consiste en aclarar la relación entre las reglas performativas necesariamente presupuestas en los actos de habla que componen el discurso y las normas morales que deben orientar todas las acciones humanas. Para cumplir este objetivo, comienzo considerando algunas teorías de la acción humana a fin de examinar una taxonomía plausible de los tipos de reglas que orientan el obrar y así poder distinguir de manera preliminar las reglas performativas y las normas morales (1). Luego examino el carácter constitutivo de las reglas performativas necesariamente presupuestas en los actos de habla que componen el diálogo argumentativo llamado "discurso", prestándoles especial atención a las que portan un contenido moral (2). A continuación reconstruyo brevemente algunas objeciones a la ética del discurso que se basan en la mencionada diferencia entre reglas discursivas y normas morales (3). Las respuestas disponibles a estas objeciones dejan formulado el problema de considerar a una misma regla como un presupuesto constitutivo necesario y como una norma moral obligatoria. Para resolver este problema advierto que esa regla rige tanto los actos de habla del interlocutor discursivo como las acciones del actor en el mundo de la vida (4). Por último, examino la cuestión del alcance de las reglas del discurso atendiendo a la conexión interna entre la acción y el posible discurso sobre ella que siempre la acompaña, conexión tácitamente contenida en la noción de responsabilidad moral (5).

1. Las teorías filosóficas sobre la acción reconocen, por lo general, una gran diversidad de tipos de comportamiento humano. Algunas de estas teorías proponen organizar conceptualmente esta diversidad tomando como unidad de análisis las denominadas "acciones básicas" (basic actions), es decir, los movimientos corporales mediante los que serían ejecutadas otras acciones más complejas. Estas acciones básicas son el punto de partida para la formulación de una serie de descripciones e interpretaciones de la acción, ordenadas en una secuencia de complejidad creciente. ${ }^{1}$ Otras teorías, en cambio, prefieren conservar la diferencia conceptual entre acción humana en sentido estricto, operación y movimiento corporal, mediante el postulado de una suerte de estratificación categorial en la que las dos últimas nociones son concebidas no sólo como la infraestructura de la primera, sino también como comportamientos coejecutados con las acciones en sentido estricto. ${ }^{2}$

\footnotetext{
${ }^{1}$ Sobre el mencionado concepto de acción básica, véase Danto (1973); Davidson (1980). Para una crítica de esta concepción fisicalista de las acciones básicas, véase Goldmann (1970). Sobre la mencionada serie de descripciones e interpretaciones, véase Feinberg (1976), pp. 139-174.

2 Una reconstrucción completa de la mencionada estratificación categorial es presentada por J. Habermas (1984 a), pp. 273-306. Para una crítica de la asimilación de los conceptos de acción y operación, véase: Böhler (1985).
} 
Para cumplir con el objetivo del presente trabajo basta con considerar brevemente aquí sólo la diferencia entre operaciones y acciones, prestándole especial atención a la naturaleza de las reglas que rigen cada una. Inspirados en la teoría del significado formulada por Ludwig Wittgenstein en sus Investigaciones filosóficas, algunos filósofos han intentado concebir la acción humana recurriendo al modelo de la observancia consciente de una regla y a la noción de juego de lenguaje. ${ }^{3}$ Este intento pretende derivar el concepto de acción intencional de una comprensión de las reglas intersubjetivas y convencionales que rigen un juego de lenguaje establecido, eliminando toda referencia a la expresión de los estados de la conciencia del agente. La observancia de una regla de cálculo aritmética o de una regla gramatical para el uso de un predicado en un lenguaje natural es propuesta como una matriz conceptual para comprender el sentido de las acciones humanas regidas por normas socialmente aceptadas.

Un balance preliminar de la observancia de reglas operacionales como modelo para comprender la acción humana permite apreciar, por un lado, que tanto en esa observancia como en esta acción nos encontramos con un agente que sabe, al menos implícitamente, que sigue una regla y del que puede esperarse que, en condiciones apropiadas, pueda indicar explícitamente la regla que está siguiendo. ${ }^{4}$ A diferencia de lo que ocurre con las regularidades descubiertas en las investigaciones neurológicas y etológicas, un agente humano es alguien que sigue reglas de un modo más o menos consciente. La conciencia de estas reglas constituye un elemento imprescindible de las competencias cognitiva, lingüística y práctica de este tipo de agente. Por otro lado, sin embargo, existen al menos dos significativas diferencias entre las reglas operacionales (por ejemplo, aritméticas, lógicas o gramaticales) y las reglas prácticas, es decir, las que rigen las acciones en sentido estricto. Una primera diferencia entre ambos tipos de reglas consiste en lo siguiente. Las reglas operacionales permiten al agente realizar una operación y al observador comprenderla, o sea, identificarla como una operación particular, distinta de otras. Pero estas reglas no le permiten al observador explicar por qué el agente realiza esa operación en una situación determinada, ni le permiten al agente alegarlas como razones que justifiquen la realización de la misma.

Las operaciones lógicas, matemáticas y gramaticales son realizadas por sujetos competentes a los que puede atribuirse tanto la capacidad de aplicar intuitivamente reglas, como la de identificarlas explícitamente. Ante la pregunta por el tipo de operación que está realizando, el agente debe poder indicar la regla que la hace com-

\footnotetext{
3 La mencionada teoría del significado se encuentra formulada en: Wittgenstein (1984). Ejemplos de teorías de la acción inspiradas en esa teoría del significado pueden encontrarse, por ejemplo, en Winch (1954) y von Wright (1963).

${ }^{4}$ Un agente competente no sólo sabe implícitamente las reglas que está siguiendo cuando actúa, sino que es capaz de explicitarlas. Sobre este saber del agente véase: Damiani (2009), pp. 60-113.
} 
prensible. Su competencia operacional le permite emplear correctamente reglas y es suficiente para saber el tipo específico de operación realizada en cada caso, es decir, para resolver la cuestión del sentido de su operación. Sin embargo, dichas reglas no le permiten al agente dar razón de la realización de esa operación en una circunstancia determinada.

En el caso de las acciones, en cambio, los agentes se orientan por reglas prácticas. Mediante estas reglas, los agentes pueden no sólo identificar y hacer comprensibles sus acciones, sino también intentar dar razón de ellas. Este intento será diverso según el tipo de acción realizada por el agente. ${ }^{5} \mathrm{Si}$ se trata de una acción instrumental, estará orientada por una regla técnica, que prescribe los medios adecuados para manipular objetos según un propósito subjetivo del agente. Si se trata de una acción estratégica, estará orientada por una regla que prescribe los medios adecuados para influir en las decisiones de adversarios, con los que el agente compite. En estos dos casos la regla de acción será una buena razón para actuar sólo si expresa un conocimiento verdadero de regularidades empíricas naturales, en el primer caso, y sociales, en el segundo. Por último, si se trata de una acción comunicativa, estará orientada por una norma que regula las expectativas comunes y recíprocas de los participantes de una interacción social cooperativa. En este caso, la norma es una buena razón para actuar sólo si es racionalmente admisible para los afectados por esa acción. En los tres tipos de acción, por tanto, las reglas prácticas no sólo permiten identificar y hacer comprensibles los comportamientos que regulan, sino también dar razones de la realización de los mismos.

Una segunda diferencia entre reglas operacionales y reglas prácticas reside en lo siguiente. Las reglas prácticas presuponen la existencia de un contexto que puede ser manipulado, influido o modificado por las acciones que ellas regulan. Tanto este contexto como el mismo tipo de comportamiento de los agentes existen previa e independientemente de las reglas prácticas. En otros términos, el mundo natural y el mundo social son realidades preexistentes al momento en que los agentes conocen, dominan y aplican las reglas técnicas que les permiten maximizar su beneficio privado y las normas que les permiten organizar su convivencia. Las reglas operacionales, en cambio, son constitutivas de las operaciones que regulan. Es decir, las operaciones lógicas matemáticas o gramaticales sólo pueden ser realizadas por un sujeto competente, que domine el sistema de reglas que permite realizarlas.

La denominada filosofía del lenguaje ordinario ha presentado la segunda diferencia mencionada entre operación y acción en términos de una distinción entre reglas regulativas y reglas constitutivas. ${ }^{6}$ Las reglas regulativas rigen comportamientos cuya existencia es previa a la formulación de las reglas y lógicamente independiente de éstas; por ejemplo, reglas de etiqueta tales como "se debe tomar el

\footnotetext{
5 Sobre esta clasificación de tipos de acción humana, véase Habermas (1981), pp. 369-452.

${ }^{6}$ Cf. Searle (1969), pp. 33-41.
} 
cuchillo con la mano derecha" o "los oficiales deben llevar corbata a la cena". La precedencia y la independencia lógica de las acciones prescriptas implican lo siguiente. Aunque estas reglas nunca hubiesen sido formuladas, el comportamiento de los agentes que ellas prescriben podría describirse igualmente como " $\mathrm{X}$ tomó el cuchillo con la mano derecha" o "el oficial X llevó corbata a la cena". Estas descripciones pueden ser formuladas por un hablante que desconoce las mencionadas reglas de etiqueta. Estas reglas son regulativas porque una acción regida por ellas puede ser descripta como tal con independencia de dichas reglas.

Para aclarar la cuestión, puede pensarse en un diálogo entre quien sabe que existen las reglas de etiqueta mencionadas y un interlocutor que las ignora. En ese diálogo, ambos podrían comprender las descripciones mencionadas de las acciones de $\mathrm{X}$. Ello se debe a que el conocimiento de una regla regulativa no es una condición necesaria para comprender una descripción de una acción que cumple con ella. Esta regla no constituye parte del significado de la acción que rige y la comprensión de esta acción, por tanto, es independiente de la regla. Ahora bien, si en ese diálogo se planteara la pregunta por las razones que justifican las acciones descriptas, sólo quien conoce las reglas podría responder "X tomó el cuchillo con la mano derecha porque se debe tomar con esa mano" o "el oficial X llevó corbata a la cena porque los oficiales deben llevarla en esas ocasiones". El interlocutor que ignora las reglas de etiqueta, en cambio, no podría ofrecer estas respuestas, a pesar de comprender las acciones mencionadas. Por lo tanto, las reglas regulativas, por un lado, rigen acciones que pueden describirse con independencia de ellas y, por otro, permiten justificar esas acciones.

Las reglas constitutivas, en cambio, crean o definen nuevas formas de conducta, por ejemplo, las reglas de juegos como el fútbol o el ajedrez. En este caso, actividades descriptas como "X hizo un gol" o "X hizo jaque mate" están constituidas por la observancia de las reglas de estos juegos que determinan o definen cuándo se hace, respectivamente, un gol o jaque mate. Si estas reglas no existiesen, dichas actividades no podrían ser descriptas de la misma manera. Para aclarar la cuestión, puede pensarse en un diálogo entre quien conoce las reglas del ajedrez y un interlocutor que las ignora. Sólo el primero podría describir una acción diciendo "X hizo jaque mate". El segundo no podría comprender esa descripción porque no sabe el significado de la expresión "jaque mate".

La diferencia mencionada entre reglas regulativas y reglas constitutivas es utilizada por la filosofía del lenguaje ordinario. Esta filosofía identifica la actividad de hablar un lenguaje con la realización de actos de acuerdo con reglas constitutivas subyacentes y denomina a estos últimos "actos de habla". Por ejemplo, para realizar el acto de prometer un hablante competente aplica, de manera más o menos consciente, una regla que define la promesa como un determinado tipo de expresión de un lenguaje natural, que en ciertas condiciones cuenta como un compromiso vin- 
culante para el hablante. Dado que los distintos idiomas o lenguajes naturales son intertraducibles, sus distintos sistemas de convenciones plasman o manifiestan en cada uno las mismas reglas constitutivas subyacentes de la promesa.

De esta manera, la filosofía del lenguaje ordinario pretende explicar la actividad de hablar un lenguaje, o sea, de realizar actos de habla en un lenguaje natural, como el español o el inglés, asimilándola a la actividad de jugar un juego como el fútbol o el ajedrez. Dicha filosofía intenta apoyar esta asimilación en las semejanzas señaladas. Una expresión lingüística formulada según las reglas del idioma español sólo puede ser comprendida por quien conoce esas reglas. Quien no sabe español sólo registra una sucesión incomprensible de sonidos. De manera análoga, sólo quien conoce las reglas del ajedrez puede comprender como "jaque mate" el movimiento de un trozo de madera sobre un tablero. La asimilación de las reglas lingüísticas con reglas de juego es presupuesta en el concepto de "juego de lenguaje" elaborado por Wittgenstein. Esta asimilación del lenguaje con un juego o con un conjunto de juegos es, sin embargo, deficitaria por varias razones. Aquí nos interesa, sobre todo, la siguiente. Existe una importante diferencia entre las reglas constitutivas subyacentes a las operaciones lógicas, matemáticas y lingüísticas, por una parte, y las de los juegos como el ajedrez y el fútbol, por otra. Esta diferencia reside en que las primeras permiten realizar actividades, como calcular y hablar, imprescindibles en lo que puede denominarse la infraestructura de las acciones humanas en general. En otras palabras, las reglas operacionales contribuyen a resolver problemas derivados de la manipulación de objetos, de la influencia sobre la toma de decisiones ajenas y del recíproco entendimiento comunicativo entre co-sujetos. En cambio, las reglas de juegos como el fútbol o el ajedrez no contribuyen a la resolución de dichos problemas y, por ello, las mismas son desconocidas por sociedades enteras a lo largo de la historia de la humanidad. ${ }^{7}$ La mencionada diferencia entre las reglas de un juego y las reglas operacionales remite, por tanto, a la conexión intrínseca de estas últimas con las acciones humanas en general. Las acciones instrumentales, estratégicas y comunicativas dependen de operaciones lingüísticas, regidas por reglas gramaticales y lógicas. Esta dependencia reside en que para plantear claramente y resolver efectivamente los problemas derivados de dichas acciones son necesarias las operaciones que componen un discurso. A continuación me detendré a examinar un aspecto específico de la mencionada conexión ente acción y discurso.

2. En el apartado anterior intenté distinguir de manera preliminar las reglas operacionales de las reglas prácticas. Las primeras rigen, por ejemplo, actos de habla como las promesas, las preguntas, las afirmaciones, etc. Las segundas, en cambio, rigen las acciones humanas instrumentales, estratégicas y comunicativas. Algunas

7 Cf. Habermas (1984 a), pp. 302-306. 
de las reglas que rigen este último tipo de acción se denominan normas morales. También señalé que si bien las reglas operacionales se asemejan a las reglas de juego por su carácter constitutivo, se distinguen de ellas por contribuir a la solución de problemas referentes a las acciones humanas en general. En este apartado me ocuparé de examinar con más cuidado un tipo de reglas operacionales particulares, a saber, sólo las que rigen el conjunto específico de actos de habla que conforman el discurso. El objetivo de este examen consiste en mostrar que algunas de estas reglas tienen un contenido moral.

Dado que el término "discurso" tiene distintos significados en la historia de la filosofía y en la filosofía contemporánea, quisiera comenzar especificando el que aquí le asigno. ${ }^{8}$ Entiendo por discurso un cierto tipo de diálogo argumentativo, consistente en el conjunto de actos de habla realizados por quienes intentan conocer o juzgar racionalmente. Los interlocutores que participan de este diálogo pretenden contribuir con sus actos a la solución de algún problema teórico o práctico, es decir, pretenden que sus actos valgan como tales contribuciones. Quien propone dicha solución pretende que ella sea la respuesta válida (verdadera o justa) al problema y así deben poder comprenderla sus posibles interlocutores. El discurso es el único medio disponible para resolver la pretensión de validez elevada por el proponente. Los interlocutores ofrecen en este diálogo argumentos y contra-argumentos para determinar si dicha pretensión resulta justificada $y$, por tanto, si la propuesta de solución al problema tratado resulta racionalmente satisfactoria. ${ }^{9}$

El discurso es entonces un tipo específico de interacción lingüística realizada para resolver pretensiones de validez. Los interlocutores discursivos realizan actos de habla regidos por reglas constitutivas subyacentes. ${ }^{10} \mathrm{El}$ cumplimiento de estas

\footnotetext{
8 Sobre los diversos significados recibidos por este término a lo largo de la historia de la filosofía véase Böhler, Gronke (1994), pp. 764-819. El postestructuralismo francés, por ejemplo, trata a los discursos como un tipo de prácticas sociales entre otras, que tienen su eficacia sobre la sociedad y obedecen a estrategias en conflicto. El historiador (arqueólogo o genealogista) se encarga de describir las condiciones fácticas en que estos discursos se forman, se transforman y se correlacionan en diferentes niveles de oposiciones. Cf. por ejemplo, Foucault (1969), (1980). Esta perspectiva, que reduce el discurso a una herramienta de poder microfísico, ha sido reasumida por la teoría sociológica de los campos, la que también utiliza la noción de acto de habla. Cf. Bourdieu (1982).

9 El discurso se distingue, entonces, tanto de otros tipos de diálogo en general como de otros tipos de diálogo argumentativo en particular. La clave de esta distinción consiste en el objetivo del discurso: la resolución argumentativa de pretensiones de validez. Este objetivo no es perseguido por los participantes de todo diálogo, ni siquiera por los de todo diálogo argumentativo. En los ámbitos pedagógico, terapéutico y retórico los interlocutores alegan argumentos pero no intentan resolver pretensiones de validez sino que buscan otras finalidades, tales como la transmisión de conocimiento, la curación del paciente y la persuasión de un auditorio particular.

10 Algunas de ellas han sido reconstruidas y explicitadas del siguiente modo: ninguno debe contradecirse; cada uno debe afirmar sólo lo que cree; distintos hablantes no pueden usar la misma expresión con distintos significados; todos deben fundamentar lo que afirman o dar razones que justifiquen el rechazo de una fundamentación; todos pueden introducir y problematizar cualquier aserción, etc. Cf.
} 
reglas es constitutivo o definitorio del rol de interlocutor discursivo; es decir, las mismas son condiciones necesarias del discurso porque quien no las cumple no puede participar en el discurso. Sin la pretensión de agotar dichas condiciones y a manera de ejemplo puede señalarse aquí que para participar del discurso es necesario admitir la validez de tres exigencias: ningún posible interlocutor debe ser excluido arbitrariamente de la participación en el discurso (1), quienes participan en el mismo deben juzgar atendiendo sólo al peso de los argumentos (2) y los participantes deben reconocerse recíprocamente el mismo derecho de presentar objeciones y el mismo deber de alegar razones (3).

A fin de aclarar estas tres reglas discursivas cabe advertir que las acciones de los interlocutores discursivos remiten necesariamente a todos los posibles interesados en la solución del problema objeto del discurso, o sea, a todos los usuarios de signos, considerados como interlocutores posibles o virtuales y no sólo a los interlocutores fácticos que el proponente encuentre en un momento dado. Ello significa, por un lado, que la comunidad de los interlocutores discursivos no puede ser limitada arbitrariamente a un círculo particular de interlocutores, por ejemplo los discípulos de una escuela filosófica, los fieles de una religión, los ciudadanos de un Estado, etc. Por otro lado, quien eleva una pretensión de validez en el discurso espera necesariamente que sus posibles interlocutores contribuyan a resolverla mediante argumentos. Esta expectativa contiene lo que podría denominarse una limitación necesaria (i.e.: no arbitraria) del círculo de los participantes en el discurso. Quienes no contribuyen mediante argumentos y contra-argumentos al proceso de resolución de las pretensiones de validez, sino que intentan distorsionarlo o impedirlo, por ejemplo, mediante amenazas y sobornos, no cuentan como interlocutores en el discurso. Estos interlocutores se atribuyen recíprocamente una disposición a determinar su juicio sólo mediante argumentos y contra-argumentos, o sea, sólo por el peso de las razones y, por consiguiente, a desactivar toda otra motivación que pueda impedir o disminuir dicha determinación discursiva del juicio. ${ }^{11}$

Los interlocutores discursivos son, por tanto, todos los que están dispuestos a determinar su juicio exclusivamente atendiendo a la validez de los argumentos presentados. Estos interlocutores mantienen entre sí, necesariamente, una relación simétrica consistente en lo siguiente. Todos los participantes tienen el mismo derecho a formular objeciones y el mismo deber de alegar razones. Esta simetría o igualdad de consideración de los participantes es, por ende, otra regla constitutiva subyacente o condición necesaria del discurso.

El carácter necesario de las reglas discursivas ha sido probado por la pragmática trascendental mediante el denominado argumento reflexivo de la fundamentación

Alexy (1978), pp. 22-58; (1996), pp. 361-367. Véase también: Apel (1998), pp. 156-164; Kettner (1993), pp. 187-211.

11 Cf. Habermas (1971), pp. 101-141. 
última. ${ }^{12} \mathrm{El}$ mismo ofrece un procedimiento que permite determinar si una regla constitutiva subyacente al discurso es también una condición de posibilidad universal y necesaria del discurso, es decir, una presuposición a priori y trascendental del mismo. Este procedimiento contiene dos pasos, consistentes en intentar negar e intentar deducir dicha regla. Si al intentar negarla se produce una autocontradicción performativa y al intentar deducirla se produce una petición de principios pragmática, entonces la regla en cuestión es un presupuesto trascendental del discurso. Una auto-contradicción performativa es una contradicción entre las dos partes que constituyen la "doble estructura" de los actos de habla: la parte proposicional y la parte performativa. ${ }^{13}$ La primera porta el contenido semántico o locucionario del acto de habla; la segunda indica la fuerza ilocucionaria del mismo. Una petición de principios pragmática se produce cuando la regla que se intenta deducir como una conclusión a partir de premisas ya se encuentra presupuesta en la parte performativa del acto de habla de deducirla. Este procedimiento tiene una naturaleza reflexiva, o mejor dicho "estrictamente reflexiva", porque quien lo aplica no debe adoptar la actitud objetivante de un observador que considera a la distancia la afirmación y los intentos de negación y deducción de la regla, sino la de un participante en el discurso actual que considera reflexivamente con su interlocutor tanto su propia afirmación de la regla, como sus intentos efectivos de negarla y deducirla. ${ }^{14}$

A fin de aclarar este procedimiento es posible ilustrarlo con el ejemplo de la última de las reglas mencionadas, a saber, la de la simetría de los interlocutores discursivos: éstos tienen el mismo derecho a formular objeciones y el mismo deber de alegar razones, que en adelante llamaremos "p". Para aplicar el argumento reflexivo de la fundamentación última es necesario, en primer lugar, intentar negar con sentido esta regla. El resultado de esta negación podría ser: "algunos interlocutores discursivos carecen del derecho a formular críticas, mientras que otros no necesitan alegar razones", que en adelante llamaremos " p". La dificultad de esta expresión puede advertirse si se explicita la parte performativa de la misma. Esta explicitación puede comenzar por aclarar la fuerza ilocucionaria y la pretensión de validez del acto realizado al usar esa expresión. Para ello, el hablante debería decir, por ejemplo, "yo sostengo como normativamente correcto que $\sim$ p". Mediante este acto el hablante aclara a sus potenciales interlocutores, por un lado, que no está haciendo una promesa, una pregunta o una apuesta, sino que está negando $\mathrm{p}$ y, por otro, que pretende validez (corrección normativa), es decir que al negar p no está relatando un sueño, ni recitando un libreto teatral, ni enunciando un ejemplo gramatical del uso del verbo "carecer" en español, sino que efectivamente niega la simetría de los interlocutores discursivos.

\footnotetext{
12 Cf. Kuhlmann (1985).

13 Cf. Habermas (1984 b), pp. 353-440.

14 Cf. Kuhlmann (1985); Böhler (1997), pp. 145-162.
} 
Un segundo paso de esta explicitación podría señalar al destinatario de la pretensión mencionada, por ejemplo, del siguiente modo: "yo sostengo ante todos los posibles interlocutores discursivos como normativamente correcto que $\sim \mathrm{p}$ ". Mediante este segundo paso, el hablante señala quiénes pueden juzgar la pretensión de validez elevada por su acto y cómo deben proceder para juzgarla: todo posible hablante que se comporte como un interlocutor discursivo, es decir que considere los argumentos y contra-argumentos relevantes para determinar si dicha pretensión se encuentra justificada racionalmente o no. En otras palabras, el destinatario del acto de habla, que debe juzgar la pretensión de validez elevada en el mismo, no pertenece a un círculo elegido libremente por el hablante (los miembros de un club, los fieles de una religión, los ciudadanos de un Estado, etc.), ni un grupo indeterminado que se comporte arbitrariamente frente a la pretensión mencionada. Este segundo paso se encuentra implícito en el primero, porque quien pretende validez para un enunciado reconoce necesariamente que su pretensión sólo puede resolverse mediante el discurso, es decir, mediante la consideración de todos los posibles argumentos a favor y en contra de la misma.

Un tercer paso de esta explicitación podría aclarar una condición que cumplen o una relación que necesariamente mantienen los destinatarios de la pretensión elevada al afirmar "p", por ejemplo, del siguiente modo: "yo sostengo ante los posibles interlocutores discursivos, quienes se atribuyen y se reconocen recíprocamente el mismo derecho a formular objeciones y el mismo deber de alegar razones, como normativamente correcto que $\sim$ p". Mediante este tercer paso el hablante aclara que los destinatarios de su acto de habla no mantienen entre sí cualquier tipo de relación libremente establecida entre ellos, sino que mantienen y reconocen una relación de simetría que los caracteriza como interlocutores discursivos. Este tercer paso no es arbitrario sino que se encuentra implícito en el segundo, porque la pretensión de validez elevada por un hablante sólo puede resolverse, positiva o negativamente, si los miembros del tribunal que debe juzgarla no encuentran obstáculos en su tarea. Si se impidiese a algunos miembros de dicho tribunal el ejercicio del derecho a formular objeciones y se eximiese a otros miembros del deber de alegar razones, la resolución discursiva de pretensiones de validez encontraría un obstáculo, porque de esa manera quedarían sin considerar un conjunto de argumentos posibles, a saber, las objeciones y las razones no pronunciadas.

Esta aplicación de la primera parte del procedimiento denominado "argumento de la fundamentación última" concluye reponiendo el significado de " p" en el acto de habla completo, es decir, agregando la parte proposicional a la parte performativa explicitada mediante los tres pasos indicados. Ello da como resultado el siguiente acto de habla:

Sostengo como normativamente correcto ante todos los posibles interlocutores discursivos, a quienes reconozco el mismo derecho a formular objeciones y el mismo deber 
de alegar razones, que algunos de ellos carecen del derecho a formular objeciones y otros no necesitan alegar razones.

Mediante esta presentación del acto de habla examinado se muestra claramente la dificultad del mismo, consistente en la contradicción entre su parte performativa (antes del término "que") y su parte proposicional (después de dicho término). La dificultad reside, entonces, en que no es posible negar la simetría de los interlocutores discursivos sin presuponerla. Esta contradicción es motivo suficiente, según el procedimiento aquí ilustrado, para considerar que la simetría negada en la parte proposicional de este acto es una condición universal y necesaria (a priori) que hace posible cualquier acto discursivo y, por tanto, también el acto de negarla. Esta condición trascendental del discurso se encuentra presupuesta en la parte performativa de todo acto de habla que pueda formar parte de un discurso.

El procedimiento se completa mediante el intento de deducir, a partir de premisas independientes, la simetría de los interlocutores discursivos. Dicho intento podría formularse del siguiente modo: "los interlocutores discursivos tienen el mismo derecho a formular objeciones y el mismo deber de alegar razones porque los interlocutores discursivos son personas y las personas tienen los mismos derechos y deberes". Quizás la dificultad que nos interesa de esta deducción no aparece a primera vista, pero puede percibirse claramente si se explicita algo contenido necesariamente en la parte performativa del acto de habla que la afirma, a saber, el mismo presupuesto trascendental de la simetría discursiva que hemos señalado más arriba. El siguiente acto de habla explícito presenta la mencionada dificultad:

Sostengo como normativamente correcto ante los posibles interlocutores discursivos, a quienes reconozco el mismo derecho a formular objeciones y el mismo deber de alegar razones, que los interlocutores discursivos tienen el mismo derecho a formular objeciones y el mismo deber de alegar razones porque ellos son personas y las personas tienen los mismos derechos y deberes.

En esta presentación del acto de habla examinado se muestra claramente la siguiente dificultad. La conclusión del razonamiento deductivo, afirmada en la parte proposicional (después del término "que" y antes del término "porque"), se encuentra necesariamente presupuesta en la parte performativa (antes del término "que"). La dificultad reside, entonces, en que no es posible deducir la simetría de los interlocutores discursivos sin presuponerla, es decir, sin cometer una petición de principios pragmática. Esta petición de principios es motivo suficiente, según el procedimiento aquí ilustrado, para considerar que la simetría deducida en la parte proposicional de este acto es una condición trascendental del discurso. ${ }^{15}$

15 Karl-Otto Apel ha insistido en el carácter trascendental de los presupuestos del discurso explicitados y fundamentados mediante el procedimiento aquí mencionado. Cf. Apel (1973), (1998). 
El argumento de la fundamentación última reflexiva, ilustrado aquí con la regla de la simetría discursiva, puede ser aplicado a las otras dos reglas mencionadas y a toda otra regla para determinar si una regla es un presupuesto de carácter constitutivo, subyacente y necesario del discurso en general, es decir, una condición trascendental del mismo. Este carácter de las reglas testeadas por el procedimiento indicado significa que, cuando las condiciones exigidas por estas reglas no se cumplen, el proceso de resolución discursiva de pretensiones de validez no puede siquiera comenzar. El interlocutor discursivo no se encuentra habilitado para elegir si acepta o rechaza estas condiciones, sino que necesariamente las cumple. Por ello, las reglas que establecen estas condiciones no pueden ser confundidas con convenciones, cuyo contenido esté determinado por el arbitrio de quienes las establecen, ni tampoco con reglas de un juego, que los jugadores pueden libremente convenir en variar o eliminar. No se trata, entonces, de reglas contingentes, sino de exigencias necesarias, condiciones constitutivas del discurso, cuya satisfacción se encuentra siempre ya presupuesta por quienes participan en él.16 Quien intenta rechazar estas reglas, sin advertirlo, las acepta, porque ese intento lo hace ante todos los posibles interlocutores que, con igualdad de derechos y deberes, contribuyan con argumentos a la resolución de sus pretensiones. Mediante esta explicitación reflexiva del intento de rechazar estas reglas, ilustrado aquí con el caso de la simetría discursiva, queda claro que dicho intento adolece de cierta inconsistencia pragmática, porque su parte performativa presupone necesariamente lo que su parte proposicional niega explícitamente.

Un aspecto relevante para el objetivo del presente trabajo reside en que las reglas aquí mencionadas prescriben determinados deberes, que por lo general se denominan morales: no excluir arbitrariamente o discriminar a las personas, resolver sus controversias mediante argumentos y reconocerlas iguales en derechos y deberes. Ello significa que algunas de las reglas constitutivas subyacentes a los actos de habla que forman parte del discurso tienen un contenido moral. Este hecho ha permitido, por un lado, la formulación de la ética del discurso como tal, que encuentra en la segunda regla mencionada el denominado principio ético procedimental o metanorma, utilizable para determinar el valor moral de las máximas y de las acciones regidas por ellas. ${ }^{17}$ Por otro lado, el contenido moral de las reglas del discurso ha sido sometido a diversas objeciones filosóficas. Algunas de ellas serán examinadas brevemente a continuación.

3. Según lo indicado en el apartado anterior, el discurso se compone de actos de habla que presuponen condiciones necesarias y constitutivas de sentido, algunas de

\footnotetext{
16 Para una crítica de la asimilación de la argumentación con un juego del lenguaje véase: Øfsti (1994), pp. $44,53-55$.

17 Sobre la formulación de ese principio, véase: Habermas (1983), pp. 103; (1996); Apel (1988), p. 123; Böhler (1992), pp. 201-231.
} 
las cuales parecen tener un carácter ético-normativo. Estas condiciones son necesarias y constitutivas porque dichos actos no pueden realizarse si las mismas no se cumplen. Sin embargo, una característica distintiva de una norma ética consiste en que su cumplimiento depende exclusivamente del arbitrio del agente. El concepto de una obligación moral remite a una situación en la que el actor puede decidir libremente si realiza una acción prescripta por una norma. Alguien es, entonces, responsable por una acción sólo si la ha realizado libremente. Por lo tanto, a diferencia de lo que ocurre con las reglas constitutivas, las obligaciones derivadas de las normas morales no siempre son cumplidas sino que siempre deben ser cumplidas.

Esta diferencia conceptual entre las reglas constitutivas del discurso y las normas morales plantea, entonces, la exigencia de explicar que una condición constitutiva, presupuesta como necesariamente cumplida, tenga el significado de una obligación moral, cuyo cumplimiento depende de una decisión voluntaria del actor. La relevancia del problema planteado se deriva del hecho de que la ética del discurso pretende fundamentar la moralidad en un principio ético procedimental o metanorma presupuesto necesariamente como una condición constitutiva del discurso. Por ello, la diferencia conceptual mencionada ha servido como ocasión para formular, al menos, tres objeciones a dicha teoría ética. 18

La primera objeción se ha presentado como el reproche de cometer una "falacia intelectualista", consistente en pretender fundamentar la obligatoriedad de las normas morales, obligatorias en la praxis, sobre la única base de principios racionales, tales como las condiciones necesarias de la argumentación. ${ }^{19}$ Según este reproche, comete una falacia intelectualista quien ignora la diferencia entre las reglas constitutivas del discurso y las normas morales que prescriben la acción responsable dentro de los conflictos de intereses de las interacciones sociales. En el discurso no hay conflictos de intereses sino sólo un interés único y común en la solución cooperativa de un determinado problema, es decir, la búsqueda de la verdad mediante la investigación científico-natural. Esta objeción concede la existencia de reglas que determinan el comportamiento de los interlocutores discursivos, pero les niega relevancia moral a las mismas por la ausencia de un conflicto de intereses. El interés compartido de los investigadores no afecta ni es afectado por las normas que regulan las acciones responsables en un mundo social conflictivo.

Esta primera objeción depende de una determinada concepción de la praxis y de la moralidad, según la cual el discurso racional y las obligaciones morales son dos ámbitos ajenos entre sí. Las condiciones normativas del discurso racional serían, según esta concepción, imperativos meramente hipotéticos y, como tales, no podrían tener relevancia moral, porque valdrían sólo para quienes quieren participar del

${ }^{18}$ Leandro Paolicchi presenta una exhaustiva reconstrucción crítica y una convincente réplica de estas objeciones en su reciente trabajo: Paolicchi (2014).

19 Cf. Ilting (1994). 
discurso. El fundamento de las obligaciones morales no se encontraría entre tales condiciones sino en el libre reconocimiento recíproco de las personas como tales. De acuerdo con esta concepción, la norma fundamental de la ética exige el respeto a las personas y su única justificación radica en la descripción de las consecuencias perjudiciales de su incumplimiento generalizado. Esta norma, empero, no condiciona ni lógica ni causalmente a los individuos, que arbitrariamente pueden o bien aceptarla como obligatoria o bien rechazarla. Por lo tanto, sin una decisión originaria a favor del reconocimiento recíproco de las personas no habría, según esta concepción, ni obligaciones morales ni un derecho que pueda valer para todos los seres racionales.

A fin de evitar una representación intelectualista de la ética normativa, no se debe confundir, según esta primera objeción, la obligatoriedad moral con la verdad teórica. Un enunciado es verdadero para todos los seres racionales que por medio del discurso puedan reconocerlo como tal, esto es, para todos los que quieran determinar el valor de verdad de ese enunciado bajo las condiciones constitutivas del uso del entendimiento. Por el contrario, la obligatoriedad de las normas morales sería totalmente independiente de dichas condiciones del conocimiento, porque su único fundamento no yace en el entendimiento sino en la voluntad humana, o sea, en el reconocimiento libre y recíproco de las personas como tales. ${ }^{20}$

Una segunda objeción a la pretensión de fundamentar racionalmente la moralidad en un principio procedimental presupuesto como condición necesaria del discurso también se asienta en la diferencia entre reglas constitutivas y normas morales. Esta segunda objeción concede que los presupuestos constitutivos del discurso no pueden ser cuestionados sin autocontradicción performativa, pero rechaza que se les atribuya un contenido moral o que de ellos pueda extraerse un principio éticonormativo o metanorma procedimental del discurso. ${ }^{21}$ La razón que se alega para negarles contenido moral a las reglas del discurso consiste en que ellas no exigen iniciar o continuar el procedimiento argumentativo que constituyen, es decir, no obligan a los agentes a aceptar las condiciones que ellas mismas prescriben. Según esta objeción, las reglas constitutivas definen el discurso pero dejan en entera libertad a los agentes para decidir si quieren participar, continuar o interrumpir el discurso. Estas reglas no permiten determinar cuándo, cómo y con quién las personas están obligadas a participar en una interacción discursiva para resolver un problema teórico o práctico, sino que se limitan a indicar las características distintivas de dicha interacción. Las mismas definen el discurso como un tipo de interacción

\footnotetext{
20 La concepción sobre la que se apoya este reproche de intelectualismo parece ignorar que ningún reconocimiento meramente fáctico puede fundamentar la validez universal de la obligatoriedad moral, porque los seres humanos también pueden reconocer libre pero equivocadamente normas inmorales como obligatorias. Cf. Apel (1998), pp. 221-280.

${ }^{21}$ Cf. Wellmer (1986), pp. 102-107.
} 
humana distinto de otros, pero no permiten resolver la cuestión del inicio, la continuidad o el rechazo del discurso.

Las reglas del discurso exigen que no se excluya arbitrariamente a posibles interlocutores, que éstos atiendan exclusivamente al peso de los argumentos y que reconozcan la igualdad de sus derechos y deberes. Estas reglas son constitutivas del discurso porque quienes no las aplican no son interlocutores discursivos. Sin embargo, advierte esta segunda objeción, estas reglas se limitan a definir el discurso y no pueden, por tanto, prescribir el deber moral de entablar un procedimiento discursivo para resolver pretensiones de validez. Las reglas del discurso y las de la moral son distintas porque los juegos que se establecen mediante ellas son de diferente índole. Las reglas del discurso son constitutivas porque no pueden cuestionarse ni transgredirse sin destruir el juego de la resolución argumentativa de las pretensiones de validez. Quien no se comporta según esas reglas no cuenta como un interlocutor discursivo. Las normas morales, en cambio, no son constitutivas sino que son obligatorias para los agentes, cuyas acciones pueden ser evaluadas según ellas. La transgresión de una norma moral por medio de una acción no destruye el juego de la moralidad, porque estas normas no indican cómo se comportan los agentes sino cómo deben comportarse. Por ello, según esta objeción, las reglas constitutivas del discurso carecen de todo contenido moral.

La diferencia entre reglas constitutivas del discurso y normas morales obligatorias para la acción humana ha dado lugar a una tercera objeción contra la pretensión de fundamentar racionalmente la moralidad en un principio procedimental presupuesto como condición necesaria del discurso. Esta tercera objeción advierte que aunque los interlocutores discursivos estuvieran obligados por presupuestos éticonormativos del discurso, podrían librarse de esa exigencia cuando salieran del círculo de la argumentación. ${ }^{22}$ Esta advertencia remite a la ineficacia de las reglas del discurso para vincular las acciones humanas extraargumentativas. En ese sentido quien, por un lado, se negara a participar del discurso y, por otro, transgrediera con su comportamiento cualquier tipo de obligación ética, daría un testimonio tácito tanto de la validez meramente hipotética de las reglas del discurso, como de la inutilidad de la denominada "fundamentación última" de las mismas, reconstruida en el apartado anterior. Esta tercera objeción señala entonces que, aun cuando se reconociese que algunas reglas del discurso tienen un contenido ético-normativo y que su validez no puede cuestionarse en el discurso, las mismas son demasiado débiles para quebrar la resistencia de quien transgrede silenciosamente con sus acciones tanto estas reglas como las normas morales que podrían justificarse racionalmente mediante el discurso práctico.

Como ya se indicó más arriba, las reglas del discurso son constitutivas del mismo porque no es posible participar del mismo sin seguirlas. La contracara de

22 Véase: Habermas (1983), p. 96. 
este carácter constitutivo de las reglas discursivas residiría, según esta tercera objeción, justamente en que los seres humanos pueden elegir actuar fuera del discurso de un modo distinto al prescripto por dichas reglas, es decir, no de un modo comunicativo sino instrumental o estratégico. Las mismas no podrían contener el fundamento de los imperativos categóricos de la moral porque su validez dependería, según esta objeción, de la voluntad de argumentar. Las reglas del discurso serían obligatorias para quienes participan en él pero no para quienes no quieren participar. La manera de vincular a estos últimos a una obligación moral no podría lograrse apelando a las reglas racionales del discurso, sino sólo a las relaciones intersubjetivas comunicativamente estructuradas en el mundo social institucionalizado que Hegel denominó "eticidad". 23

Antes de pasar a aclarar, en el siguiente apartado, por qué una condición constitutiva puede contener una obligación moral, conviene presentar un breve balance conjunto de las tres objeciones mencionadas. Las mismas tienen en común, por un lado, un déficit y, por otro, un mérito. El déficit común de estas tres objeciones consiste en presuponer dogmáticamente que la moralidad es independiente de la racionalidad. La primera la hace depender exclusivamente del libre reconocimiento recíproco de las personas; la segunda y la tercera de una motivación irracional para ingresar y mantenerse en el discurso práctico. Esta representación sesgada de la moralidad impide advertir que este discurso es el único medio para determinar la corrección moral de las acciones y las normas. Sin embargo, a pesar de este déficit, las tres objeciones mencionadas tienen el mérito de señalar la necesidad de aclarar el hecho de que algunas reglas constitutivas puedan ser también moralmente obligatorias. A continuación intentaré aclarar este hecho.

4. Las objeciones mencionadas en el apartado anterior, aun cuando no se las pueda considerar del todo acertadas, tienen el mérito de dejar planteado el problema de considerar a una misma regla como una condición constitutiva del discurso a la vez que como una norma moral obligatoria. En efecto, mientras que una condición tal es siempre ya cumplida, una norma moral puede ser cumplida o no serlo. Por ello la dificultad consiste en explicar que una condición constitutiva contenga una obligación moral. Para ilustrar esta dificultad se puede volver a examinar el ejemplo mencionado más arriba. Si la igualdad de consideración de los interlocutores discursivos es ya siempre presupuesta, aceptada y respetada como válida por ellos, parece problemático sostener que la misma también debe ser aceptada y respetada como moralmente obligatoria. En el marco de la ética del discurso debe poder aclararse este pasaje de lo constitutivo a lo obligatorio, es decir, de algo que siempre ya es cumplido a algo que debe ser cumplido.

\footnotetext{
${ }^{23}$ Apel advierte que mediante este recurso a la eticidad, Habermas comete la falacia naturalista de pretender fundar la validez de las obligaciones morales categóricas en acciones comunicativas. Cf. Apel (1998), p. 663.
} 
Como es sabido, la ética del discurso se presenta como una transformación postmetafísica de la ética formulada por Immanuel Kant, quien presentó una clara diferenciación y una precisa articulación entre los conceptos de ley moral y de obligación moral. ${ }^{24}$ La mencionada diferenciación entre estos dos conceptos reside en que la ley moral vale para todo ser racional que tenga una voluntad y que, como tal, se dé a sí mismo esa ley de manera autónoma. El concepto de dicha ley no contiene aún el significado de una obligación que deba ser cumplida por seres humanos, sino sólo la idea de una ley que rige las relaciones entre seres racionales, tal como la ley natural rige las relaciones entre los fenómenos naturales. En los términos metafísicos de Kant, los miembros del mundo inteligible se comportan según la ley moral y son libres, esto es, auténticamente autónomos, porque se dan a sí mismos la ley que los rige. La articulación de los conceptos de ley y obligación es presentada por Kant del siguiente modo. La ley moral puede ser comprendida como obligación que debe ser cumplida sólo por ciertos seres racionales, a saber, por los que también pertenecen al mundo sensible, por ejemplo: los seres humanos. Sólo un ser que es a la vez miembro del mundo inteligible y del mundo sensible puede considerar la ley moral, esto es, la ley de la libertad, como una obligación. Sólo un ser racional cuya voluntad puede ser determinada no sólo por su razón, sino también por sus inclinaciones egoístas, puede considerar la ley que él mismo se da como una obligación que debe ser cumplida. Mediante su doctrina metafísica de los dos mundos, Kant intenta aclarar la posibilidad de que un principio a priori, de acuerdo con el cual actúa efectivamente un ser racional, pueda prescribir una obligación moral a los seres humanos.

La transformación postmetafísica de la ética kantiana, propuesta por la ética del discurso, exige, por un lado, superar el trasfondo metafísico del planteamiento kantiano del problema mencionado $\mathrm{y}$, por otro, lograr una formulación pragmático-lingüística del mismo problema, que conserve el núcleo de verdad de la articulación kantiana entre ley y obligación. Luego de la transformación mencionada no parece legítimo ya sostener la doctrina kantiana de dos mundos. Sin embargo, esta doctrina puede ser reformulada para aclarar el pasaje de las reglas constitutivas a las normas obligatorias, si se distinguen el rol del interlocutor discursivo y el rol del actor en el mundo de la vida, como dos posibles roles del mismo agente. 25

Quien participa del discurso presupone siempre y necesariamente condiciones constitutivas de la argumentación, que portan un contenido moral. No puede decirse, en verdad, que el interlocutor discursivo como tal deba cumplir con dichas condiciones normativas o normas morales (en términos kantianos, con la ley moral), porque él cumple necesariamente y siempre ya con dichas condiciones. Al ser con-

\footnotetext{
24 Cf, Kant (1785), pp. 453-454. Para la transformación mencionada véase: Apel (1973), Bd. II, pp. 358-436.

25 Cf. Böhler (2013 a).
} 
diciones constitutivas, quien no las cumple no puede desempeñarse como interlocutor discursivo. Estas condiciones del discurso actual (esto es, del que participamos virtualmente en este momento nosotros, el autor y el lector de estas líneas) pueden ser descubiertas y probadas mediante una reflexión estricta sobre la parte performativa de nuestros actos de habla, tal como lo señalamos en el tercer apartado de este trabajo. Si esas condiciones no fuesen aquí y ahora efectivamente cumplidas por nosotros, no las podríamos descubrir y fundamentar de manera última como condiciones constitutivas de nuestro discurso actual.

Para el interlocutor discursivo, por tanto, las reglas del discurso son a la vez constitutivas y morales, en el sentido kantiano de la ley moral, pero ellas no son para él obligaciones morales, que deba cumplir. Dicho interlocutor cumple necesariamente y siempre ya con esas condiciones, es decir, no tiene alternativa. Cuando nos atenemos exclusivamente a la validez de los argumentos, tal como nosotros estamos haciendo en este momento y, por tanto, determinamos nuestra capacidad de juzgar de manera puramente racional, sin que interfiera en nuestro juicio ninguna motivación extraargumentativa, desempeñamos el rol de interlocutor discursivo, algunas de cuyas condiciones son a la vez constitutivas y morales. Aquí y ahora nos comportamos siempre ya de acuerdo con la ley moral. Esta ley no tiene, sin embargo, para nosotros todavía el significado de una obligación que nosotros debamos cumplir y que podamos, por tanto, no cumplir. Si nosotros fuésemos sólo interlocutores discursivos, esto es, si nosotros pudiésemos querer orientar también nuestras acciones no lingüísticas sólo según criterios argumentativamente justificados, no tendríamos obligaciones morales y la palabra "deber" no podría tener para nosotros ningún significado, porque en ese caso sólo podríamos querer actuar conforme a la ley moral.

Sin embargo, nosotros no somos sólo interlocutores discursivos, sino seres humanos que podemos desempeñar el rol de tales interlocutores y que, incluso de vez en cuando, también queremos desempeñarlo. En el mundo de la vida nosotros podemos actuar no sólo según normas morales, sean éstas las que reconocemos implícitamente como un componente necesario de nuestro saber performativo, sean las que pueden justificarse mediante el discurso práctico. Nosotros podemos también transgredir las normas morales. Recién en este contexto del mundo de la vida, en el que no siempre ni de manera prioritaria desempeñamos el rol de interlocutor discursivo, las condiciones normativo-morales del discurso adquieren para nosotros el significado de obligaciones morales que nosotros debemos cumplir y podemos transgredir. ${ }^{26}$ Por lo tanto, la ley moral que en el plano del discurso tiene el significado de una condición constitutiva, siempre ya cumplida por los interlocutores, se

26 Por ello no parece del todo apropiada la expresión "transferencia de obligatoriedad" (Verbindlichkeitstransfer) utilizada para referirse a la continuidad de la validez de las reglas del discurso como normas morales en el mundo de la vida. Cf. Øfsti (1992), pp. 296-316. 
presenta en el mundo de la vida como una obligación que, bajo ciertas circunstancias, debe ser cumplida. En el mundo de la vida podemos atender tanto a la fuerza del mejor argumento como a otras motivaciones prácticas. Por ello, para nosotros, en cuanto actores del mundo de la vida, ciertas condiciones normativas del discurso tienen el significado de obligaciones morales.

5. En el apartado anterior se consideró el hecho de que una misma regla discursiva sea a la vez racionalmente constitutiva y moralmente obligatoria. La aparente dificultad del mismo se superó atendiendo a los dos vínculos que mantiene dicha regla con dos roles que todo agente humano puede asumir. Una misma regla discursiva con contenido moral es constitutiva para quien asume el rol de interlocutor discursivo y es obligatoria para quien simplemente actúa en el mundo de la vida. En este apartado se examinarán con más cuidado esos dos roles a fin de determinar no sólo su diferencia sino también su íntima relación. Este examen permitirá aclarar por qué las reglas constitutivas del discurso valen como obligatorias fuera del discurso, es decir, para toda acción humana en general.

Las acciones humanas, a diferencia de cualquier fenómeno natural, pueden ser consideradas no sólo desde la perspectiva de un observador que intenta describirlas y explicarlas objetivamente, sino también desde la perspectiva del agente, esto es, del participante de la interacción social, comprometido con la situación, los intereses y las relaciones sociales en las que le toca actuar. Puede denominarse a este rol del participante como el de actor en el mundo de la vida. Por otro lado, este participante de la interacción social puede asumir también otro rol en cuanto se plantea alguna cuestión de validez respecto del curso de acción elegido por alguno de los sujetos que interactúa. Este otro rol puede denominarse como el de interlocutor discursivo.

A fin de aclarar esta diferencia de roles, es necesario advertir que la misma no debe pensarse atendiendo a una situación en la que un individuo actúa y otro se plantea cuestiones de validez respecto del curso de acción elegido por el primero. Se trata más bien de dos actitudes que puede asumir, sucesiva o simultáneamente, un mismo individuo en una misma interacción social. En ese sentido, estos dos roles no son sólo distintos sino también inseparables y complementarios. Ello es así, por un lado, porque quien participa del discurso para contribuir a resolver colectivamente un problema teórico o práctico realiza ciertas acciones lingüísticas o actos de habla, por ejemplo: preguntar, responder, afirmar, objetar, fundamentar, etc. Es decir que el discurso es un tipo especial de interacción social y el interlocutor que participa en el discurso es ya un actor, en tanto que, mediante las acciones mencionadas, contribuye a la resolución discursiva de un problema teórico o práctico. ${ }^{27}$

27 Por ello, en realidad, la mencionada figura del observador que pretende sólo describir o explicar objetivamente una acción es una representación deficitaria del sujeto cognoscente, deudora de la idea 
Por otro lado, los dos roles mencionados son inseparables y complementarios también porque el actor del mundo de la vida siempre puede devenir interlocutor discursivo. Consideremos esta posibilidad más de cerca. Quien simplemente actúa, es decir, quien participa de la interacción no discursiva, mediante acciones lingüísticas y no lingüísticas, tanto estratégicas como comunicativas, no desempeña fácticamente el rol de interlocutor discursivo. Se trata del caso de quien no se detiene a proponer ante otros su curso de acción, ni acompaña su propuesta con una pretensión de corrección normativa que los otros pueden evaluar y, por lo tanto, tampoco ofrece argumentos para justificar racionalmente su pretensión y responder a las objeciones de sus interlocutores. Un aspecto decisivo de este rol de simple actor en el mundo de la vida consiste, sin embargo, en que quien lo desempeña, aunque no se detiene a justificar racionalmente sus acciones, podría hacerlo. Es decir, todo actor es potencialmente un interlocutor discursivo.

Este segundo aspecto de la conexión entre los dos roles mencionados reside, entonces, en que la posibilidad de participar en el discursivo se encuentra necesariamente implícita en el concepto de actor humano en general. Quien simplemente actúa sin argumentar para justificar racionalmente su comprensión de la situación, la conveniencia de los medios empleados para realizar un objetivo o la corrección moral de su acción, podría sin embargo argumentar para ello. Esta posibilidad no actualizada fácticamente puede presentarse, por ejemplo, en el caso de quien simplemente actúa y, pudiendo argumentar, no lo hace porque las circunstancias no parecen exigirlo o porque quienes interactúan con él no encuentran motivos para exigirle razones. Esta posibilidad puede pensarse también en el caso de quien, encontrándose con la exigencia de justificar la corrección moral de su acción, prefiere no hacerlo, sea porque no cree que haya razones suficientes para esa empresa, sea porque no cree contar en un momento dado con esas razones, sea porque las circunstancias parecen impedirle la implementación de un discurso práctico mediante el que se resuelvan sus pretensiones de corrección normativa. También puede pensarse en el caso de quien fácticamente no es capaz de actualizar la posibilidad mencionada y otros casos en los que un actor del mundo de la vida no actualiza la posibilidad de justificar racionalmente un curso de acción que él mismo ha elegido. Independientemente de esa variedad de casos, es necesario destacar aquí que toda acción voluntaria en el mundo de la vida puede ser moralmente juzgada como correcta e incorrecta y que el discurso práctico es el único medio para justificar racionalmente dicho juicio.

clásica de theoría, como contemplación pasiva. El déficit de esta representación reside en que la adquisición de conocimiento supone necesariamente la realización de ciertos actos, a saber, los actos que realizamos cuando participamos en un discurso. Si se atiende a estos actos, se advierte que quien conoce actúa, o mejor dicho interactúa, junto con otros en un proceso discursivo. La idea clásica de theoría hace abstracción de estas acciones discursivas, imprescindibles para el conocimiento humano. 
A fin de aclarar las razones por las que una regla constitutiva del discurso puede valer como norma moral obligatoria, según la cual pueden juzgarse acciones de agentes que no participan del discurso, es necesario advertir una condición de la posible implementación de un discurso práctico efectivo, en el que se justifique dicho juicio. Esta condición consiste justamente en el discurso que implícita y virtualmente acompaña la realización de toda acción humana en el mundo de la vida. ${ }^{28}$ Toda acción humana se encuentra orientada por el propósito del agente y este propósito presupone necesariamente cierta (pre-)comprensión del agente sobre la situación en la que le toca actuar. Es cierto que un agente puede simplemente actuar, sin presentar ante posibles interlocutores su propósito y su comprensión e, incluso, sin reflexionar en soledad sobre los mismos. Sin embargo, lo que interesa destacar aquí es que tanto el propósito del agente como su comprensión de la situación pueden ser objeto de un discurso, en el que se expliciten y evalúen las pretensiones de validez implícitas en el propósito y la comprensión que orientan y motivan la acción del agente. En otros términos, toda acción humana se realiza acompañada de la posibilidad de dos discursos; a saber, un discurso práctico en el que podría examinarse la pretensión de rectitud normativa implícita en el propósito que motiva la acción y un discurso teórico en el que podría examinarse la pretensión de verdad implícita en la comprensión que el agente tiene de la situación en la que actúa.

Esta idea de un discurso implícito acompañante de toda acción humana resulta fundamental para comprender un segundo aspecto de la ya mencionada unión indisoluble de los roles del interlocutor discursivo y del actor. Más arriba se señaló que quien participa en un discurso realiza necesariamente ciertos actos (p. ej.: preguntar, responder, afirmar, objetar, fundamentar, etc.) y que, por tanto, el interlocutor discursivo es ya un actor y no un mero espectador que contempla intuitivamente las ideas. Ahora puede advertirse un segundo aspecto de la misma unidad: el actor del mundo de la vida es ya un posible interlocutor. El propósito que motiva su acción y su comprensión de la situación en la que actúa contienen implícitamente pretensiones de validez que sólo pueden ser resueltas mediante un discurso. Si dicho propósito y dicha comprensión fuesen enunciados explícitamente mediante actos de habla regulativos y constatativos respectivamente, estos actos contendrían en su parte performativa pretensiones de validez, que sólo podrían resolverse mediante el discurso.

Este discurso virtual o posible, que acompaña la realización de toda acción en el mundo de la vida, permite que la misma sea objeto de evaluación moral aun luego de realizada. A diferencia de lo que ocurre con un fenómeno natural, tal como una reacción química o biológica, la idea de acción humana supone un agente capaz de optar por cursos de acción alternativos. Esta opción puede tornarse objeto de críti-

28 Sobre el concepto de discurso virtual acompañante véase: Böhler (2013 b), pp. 3-46. 
ca y justificación porque los propósitos del agente se comprenden como propuestas acompañadas por pretensiones de validez que sólo pueden ser resueltas mediante un discurso posible. Si se niega la posibilidad de este discurso, parece destruirse el sentido mismo del concepto de acción humana. Quien actúa con sentido en el mundo de la vida pretende implícitamente que su propósito es moralmente correcto y que su comprensión de la situación es verdadera. Por ello, esas pretensiones pueden ser rechazadas por un crítico que impugne el propósito del agente como inmoral y la comprensión de la situación como falsa. Quien simplemente actúa ya desempeña virtualmente el rol del interlocutor discursivo comprometido a contribuir con la resolución argumentativa de sus pretensiones implícitas en su acción.

El concepto de discurso virtual acompañante permite superar una confusión compartida por las objeciones mencionadas en el tercer apartado de este trabajo. Esas objeciones confunden dos cosas bien distintas: por un lado, el hecho innegable de que los seres humanos pueden decidir arbitrariamente si comienzan, continúan o interrumpen un discurso y, por otro, la problemática atribución a los agentes de la capacidad de decidir arbitrariamente si sus acciones pueden ser o no objeto de discurso. A diferencia de dichas objeciones, el sentido común parece no confundir las cosas de esta manera, porque la simple atribución de responsabilidad a un agente por su acción ya supone necesariamente la atribución de la capacidad de responder por su acción, esto es, la capacidad y la obligación de dar razones que la justifiquen. Dichas razones, en realidad, permitirían sostener en un discurso las pretensiones de validez implícitas en el propósito y la comprensión de la situación que orientan la acción. La atribución de responsabilidad contiene entonces, implícitamente y ya en el plano del sentido común, que se considere como autor de acciones a alguien capaz de proponer un curso de acción, de elevar pretensiones de validez y de contribuir a resolverlas discursivamente. El actor responsable en el mundo de la vida debe poder desempeñar el rol de interlocutor discursivo; en otras palabras, llegado el caso de que se le exija, debe poder responder ante otros que le pregunten por las razones que justificarían el curso de acción que ha elegido.

En conclusión, la noción de responsabilidad supone la relación que nos habíamos propuesto aclarar; esto es, la relación entre las reglas performativas, necesariamente presupuestas en los actos de habla que componen el discurso, y las normas morales, que deben orientar todas las acciones humanas. Esta relación consiste en que el actor del mundo de la vida debe reconocer como obligatorias las reglas que cumpliría si enunciase en un discurso práctico las razones que justificarían su curso de acción. 


\section{Referencias bibliográficas}

Alexy, R. (1978): "Eine Theorie des praktischen Diskurses", en: W. Oelmüller (Hrsg.), Materialien zur Normendiskussion. Bd. 2: Normenbegründung, Normendurchsetzung, Padeborn, F. Schöning, pp. 22-58.

Alexy, R. (1996): Theorie der juristischen Argumentation. Die Theorie des rationalen Diskurses als Theorie der juristischen Begründung, 3. Aufl., Frankfurt a. M., Suhrkamp.

APEL, K.-O. (1973): Transformation der Philosophie, Frankfurt a. M., Suhrkamp.

APEL, K.-O. (1988): Diskurs und Verantwortung, Frankfurt a. M., Suhrkamp.

APEL, K.-O. (1998): Auseinandersetzungen in Erprobung des transzendentalpragmatischen Ansatzes, Frankfurt a. M., Suhrkamp.

BöHLER, D. (1985): Rekonstruktive Pragmatik. Von der Bewußtseinsphilosophie zur Kommunikationsreflexion: Neubegründung der praktischen Wissenschaften und Philosophie, Frankfurt a. M., Suhrkamp.

BöHLER, D. (1992): "Diskursethik und Menschenwürdegrundsatz zwischen Idealisierung und Erfolgsverantwortung", en K.-O. Apel, M. Kettner (Hrsg.), Zur Anwendung der Diskursethik in Politik, Recht und Wissenschaft, Frankfurt a. M., Suhrkamp, pp. 201-231.

BöHLER, D., Gronke, H. (1994): "Diskurs”, en: G. Ueding (Hrsg.), Historisches Wörterbuch der Rhetorik, Tübingen, Max Niemayer Verlag, pp. 764-819.

BÖHLER, D. (1997): "Dialogreflexion als Ergebnis der sprachpragmatischen Wende. Nur das sich wissende Reden und Miteinanderstreiten ermöglicht Vernunft", en J. Trabant, (Hrsg.), Sprache denken. Positionen aktueller Sprachphilosophie, Frankfurt a. M., Fischer-Taschenbuch Verl., pp. 145-162.

BöHLER, D. (2013 a): Verbindlichkeit aus dem Diskurs. Denken und Handeln nach der sprachpragmatischen Wende, Freiburg/München, Verlag Karl Alber.

BöHLER, D. (2013 b): "Handlung und Begleitdiskurs oder Selbsteinholung und Mitverantwortung des leibhaften Diskurspartners", en: J. O. Beckers, F. Preußger, Th. Rusche (Hrsg.), Dialog, Reflexion, Verantwortung. Zur Diskussion der Diskurspragmatik, Würzburg, Könighausen \& Neumann.

Bourdieu, P. (1982): Ce que parler veut dire: l'économie des échanges linguistiques, Paris, Fayard.

Danto A. C. (1973): Analytical Philosophy of Action, Cambridge, Cambridge University Press.

Damiani, A. M. (2009): Handlungswissen. Eine transzendentale Erkundung nach der sprachpragmatischen Wende, Freiburg/München, Verlag Karl Alber.

Davidson, D. (1980): Essays on Actions and Events, Oxford, Oxford Clarendon Press.

FeINBERG, J. (1976): “Acción y responsabilidad”, en A. R. White (ed.), La filosofía de la acción, México, FCE, pp. 139-174. 
Foucault, M. (1969): L’archeologie du savoir, Paris, Gallimard.

FouCAUlt, M. (1980): A verdade e as formas jurídicas, Rio de Janeiro, PUCRJ.

Goldmann, A. I. (1970): A Theory of Human Action, Engelwoood Cliffs, N.J., Prentice-Hall.

HABERMAS, J. (1971): "Vorbereitende Bemerkungen zu einer Theorie der Kommunikativen Kompetenz", en J. Habermas, N. Luhmann, Theorie der Gesellschaft oder Sozialtechnologie, Frankfurt a. M., Suhrkamp, pp. 101-141.

Habermas, J. (1981): Theorie des kommunikativen Handelns, Frankfurt a. M., Suhrkamp, Bd. 1.

HABERmas, J. (1983): Moralbewusstsein und kommunikatives Handeln, Frankfurt a. M., Suhrkamp.

HABERmas, J. (1984 a): "Handlungen, Operationen, körperliche Bewegungen", en id., Vorstudien und Ergänzungen zur Theorie des kommunikativen Handelns, Frankfurt a. M., Suhrkamp, pp. 273-306.

HABERMAS, J. (1984 b): "Was heißt Universalpragmatik?", en id., Vorstudien und

Ergänzungen zur Theorie des kommunikativen Handelns, Frankfurt a. M., Suhrkamp, pp. 353-440.

HABERMAS, J. (1996): Erläuterungen zur Diskursethik, Frankfurt a M., Suhrkamp. ILting, K.-H. (1994): Grundfragen der praktischen Philosophie, Frankfurt a. M., Suhrkamp.

Kant, I. (1785): Grundlegung zur Metaphysik der Sitten, en: Kants gesammelte Schriften. Akademie-Textausgabe, Berlin, 1968.

Kettner, M. (1993): "Ansatz zu einer Taxonomie performativer Selbstwidersprüche", en A. Dorschel, et al. (Hrsg.): Transzendentalpragmatik. Ein Symposion für Karl-Otto Apel, Frankfurt a. M., Suhrkamp, pp. 187-211.

KuHlmanN, W. (1985): Reflexive Letztbegründung. Untersuchungen zur Transzendentalpragmatik, Freiburg/München, Verlag Karl Alber.

ØғSTI, A. (1992): “Ist diskursive Vernunft nur eine Sonderpraxis? Betrachtungen zum «Verbindlichkeitstransfer» von transzendental-reflexiv (letzt-) begründeten Normen", en K.-O. Apel, M. Kettner (Hrsg.), Zur Anwendung der Diskursethik in Politik, Recht und Wissenschaft, Frankfurt a. M., Suhrkamp, pp. 296-316.

Øfsti, A. (1994): Anwandlungen: Essays zur Sprachphilosophie und Wissenschaftstheorie, Würzburg.

Paolicchi, L. (2014): Praxis, sentido y normatividad, Buenos Aires, Prometeo.

Searle, J. R. (1969): Speech Acts, Cambridge, Cambridge University Press.

Wellmer, A. (1986): Ethik und Dialog. Elemente des moralischen Urteils bei Kant und in der Diskursethik, Frankfurt a. M., Suhrkamp.

Winch, P. (1958): The Idea of Social Science and Its Relation to Philosophy, London, Routledge and Kegan Paul. 
Wittgenstein, L. (1984): Philosophische Untersuchungen, en: id., Schriften. Werkausgabe Bd. 1, Frankfurt a. M., Suhrkamp.

von Wright, G. H. (1963): Norm and Action, London, Routledge and Kegan Paul.

\author{
Alberto Mario Damiani \\ Facultad de Filosofía y Letras \\ Universidad de Buenos Aires \\ damial@filo.uba.ar
}

